\title{
EFEKTIVITAS LEARNING MANAGEMENT SYSTEM CHAMILO MATERI GERAK HARMONIK SEDERHANA TERHADAP HASIL BELAJAR PESERTA DIDIK
}

\author{
Dwi Suseno Wati $^{1 *}$, Sardianto Markos Siahaan ${ }^{2}$, Ketang Wiyono ${ }^{3}$ \\ ${ }^{1,2,3}$ Program Studi Magister Teknologi Pendidikan FKIP \\ Universitas Sriwijaya, Palembang, Indonesia \\ *Corresponding Author: dwi.susenowati25@gmail.com
}

DOI: 10.24929/lensa.v11i2.166

\begin{abstract}
ABSTRAK
Penelitian ini memiliki tujuan agar mendapatkan informasi mengenai efektifitas LMS Chamilo materi gerak harmonik sederhana terhadap hasil belajar peserta didik. PreExperimental design terhadap desain penelitian one-group pretest-posttest merupakan metode yang dipakai pada penelitian ini. Peserta didik kelas X SMA Aisyiyah 1 Palembang tahun ajaran 2019/2020 $(n=30)$ menjadi subjek dalam penelitian ini. Sampel diambil berdasarkan teknik purposive sampling. Teknik pengumpulan data dilaksanakan melalui tes tertulis. Data hasil penelitian dianalisis dengan $\mathrm{N}$-gain score. Pemaparan hasil penelitian yaitu terdapat eskalasi rata-rata hasil belajar sebelum dan sehabis pemanfaatan LMS Chamilo. Rata-rata hasil belajar sebelum diberikan LMS Chamilo adalah sebesar 51,00. Kemudian pendidik memberikan pengajaran menggunakan LMS Chamilo peningkatan rata-rata skor hasil belajar kognitif peserta didik menjadi 79,00 . Peningkatan nilai rerata peserta didik diukur menggunakan $\mathrm{N}$-gain Score dan didapatkan hasil sejumlah 0,582 berkategorikan sedang. Penyimpulan data hasil penelitian ialah pemanfaatan LMS Chamilo materi gerak harmonik sederhana efektif terhadap hasil belajar peserta didik.
\end{abstract}

Kata kunci: LMS Chamilo, Gerak Harmonik Sederhana, Efektivitas

\section{ABSTRACT}

The purpose of this study is to obtain information about effectiveness of e-Learning devices simple harmonic movement materials in high school using LMS Chamilo to the students learning outcomes. The research methods used are pre-experimental design and a set of pre-test and post-test research designs. This study involved students of grade X SMA Aisyiyah 1 Palembang school year 2019/2020 $(n=30)$. Sampling using purposive sampling technique. Data collection techniques using written tests. The data of the study results were analyzed with $N$-gain score. The results show that the average learning outcomes have increased before and after using LMS Camilo. The average learning outcome before being given the Chamilo LMS was 51.00. Then educators gave teaching using LMS Chamilo increased the average cognitive learning outcome score of learners to 79.00. The increase in the average value of learners was measured using the $\mathrm{N}$-gain Score and obtained a result of 0.582 with a moderate category. Based on the results can be concluded LMS Chamilo on simple harmonic motion materials effective to the learning outcomes of learners.

Keywords: LMS Chamilo, Simple Harmonic Motion, Effectiveness

\section{PENDAHULUAN}

Pandemi Covid-19 saat ini membuat lembaga pendidikan berjalan tidak normal (Syah, 2020; Syauqi, dkk., 2020). Peralihan dari kegiatan belajar tatap muka ke 
kegiatan pembelajaran virtual membuat pendidik dan peserta didik tidak terbiasa dalam proses pembelajaran. Teknologi segera berperan lebih pesat pada pemberatasan masalah ini. Masalah penting dalam proses pembelajaran menggunakan teknologi adalah ketersediaan sarana dan prasarana. Untuk mendukung kebijakan penggunaan teknologi untuk pembelajaran, penyelenggara industri telekomunikasi Indonesia telah menyiapkan paket data gratis hingga $30 \mathrm{~GB}$ per orang untuk mengikuti pembelajaran daring (Sulisworo, dkk., 2020).

Revolusi industri keempat bukan hanya perubahan yang digerakkan oleh teknologi (Cahyati, dkk., 2021). Mulqueeny dkk., (2015) percaya bahwa persiapan tryout e-learning dapat meningkatkan hasil belajar jangka pendek atau jangka panjang peserta didik. E-learning adalah kegiatan pembelajaran yang diselenggarakan serta diperluas berdasarkan perkembangan teknologi, sehingga bisa digunakan kapan saja untuk mengatasi pembatasan antara peserta didik dan pendidik (Lin, dkk., 2017; Pertiwi dan Sumbawati, 2019). Ini menunjukkan bahwa e-learning terkait dengan penggunaan Internet.

Secara umum untuk memenuhi kebutuhan proses pembelajaran saat ini, pendidik dituntut untuk mengembangkan materi ajar sesuai dengan kebutuhan proses belajar mengajar yang efektif, efisien, dan kreatif (Alam Fajar, dkk., 2015; Ade, dkk., 2018; Jundu $d k k ., 2020$ ). Sebagian besar pendidik memberikan pembelajaran melalui perkuliahan, sehingga pembelajaran menjadi berpusat pada pendidik. Pelaksanaan pembelajaran jenis ini akan berdampak pada kinerja akademik peserta didik yang rendah (Istuningsih, dkk., 2018). Adanya kebutuhan dalam pengembangan e-learning bagi mata pelajaran fisika membuat proses pembelajaran berubah lebih efektif, efisien, dan menyenangkan. Dari hasil pengamatan dengan pendidik SMA Aisyiyah 1 Palembang dan wawancara bersama peserta didik menunjukkan adanya permasalahan dalam belajar mata pelajaran fisika adalah menganalisis pertanyaan fisika dan memahami formula fisika terutama pada materi gerak harmonik sederhana. Hal itu menyebabkan dibutuhkan lebih banyak waktu untuk bisa memahami subyek fisika. Manajemen e-Learning perlu menggunakan teknologi informasi untuk memenuhi era, sistem dan materi era digital (Elyas, 2018). Bahkan, media e-learning perkembangangannya telah menjadi media pembelajaran pada aneka macam sekolah termasuk perpendidikan tinggi (Hidayatulah,dkk., 2015; Puspita Sari dan Setiawan, 2018).

Management system of e-learning terdiri sebagai dua sistem, yaitu content management system (CMS) dan learning management system (LMS). CMS adalah situs web berorientasi konten. Kompleksitas setiap fungsi CMS tergantung pada penggunaan CMS itu sendiri (Benevolo dan Negri, 2007; Bakri dan Muliyati, 2017). Pada saat yang sama, LMS adalah e-learning dengan sistem manajemen yang banyak digunakan karena cukup untuk mengeksplorasi fungsi tersedia tanpa merancang program Web itu sendiri (Surjono, 2013; Amelia dan Gufron, 2018). LMS menyediakan proses pembelajaran inovatif yang terdiri dari bidang teknologi informasi dengan menerapkan aplikasi opensource yang tersedia secara bebas di Internet (Ghoniemy, Fahmy dan Aljahdali, 2010; Sanova, 2018). Chamilo adalah situs web gratis yang menyediakan kolaborasi dan platform online (Maes, 2010; Rahmah, Saleh dan Bharati, 2020). Selain Chamilo, ada lagi open source LMS yaitu Moodle. Moodle adalah aplikasi yang dapat mengubah media pembelajaran menjadi situs web (Irawan dan Surjono, 2018). Untuk mengakses fungsi di Moodle dan Chamilo Anda harus memiliki paket data yang merupakan kunci yang memberi pengguna hak untuk mengakses dan menggunakan fungsi layanan Web (J.A. Hijar et al., 2014). Keuntungan Chamilo daripada produk LMS lainnya adalah fungsi Chamilo memiliki gaya desain dan keragaman yang menarik bagi pendidik dan peserta didik, e-learning berbasis Chamilo menyerupai media sosial sehingga menambah ketertarikan peserta didik dalam mempelajari dan memahami materi gerak harmonik sederhana, konten pada e-learning berbasis Chamilo lengkap seperti teks, gambar, audio, video, soal, dan dapat dikembangkan pada bagian tampilan awal. Pada desain e-learning website akan tergolong baik apabila mampu memaparkan efek yang luas pada study experience siswa (Putra dan Abidin, 2020). 
Wu dkk., (2018) melakukan sebuah penelitian terkait e-learning dengan hasil adanya selisih yang berjarak ditengah kelas eksperimen dan kelas kontrol, dimana kasus ini terlihat berdasarkan keefektifan sistem e-learning yang dapat berubah secara dinamis sebagai umpan balik terhadap keunikan macam-macam peserta didik. Chun-Hui dkk., (2017) jua membuat penelitian yang terbukti efektif menggunakan melakukan eksplorasi terhadap sistem e-learning adaptif yang efektif menyokong siswa menggunakan konten pelajaran yg diadaptasi dengan eksklusif serta sukses menyokong siswa dalam perolehan nilai saintifik serta mengembagkan kemampuan kognitif. Perolehan penelitian tadi jua menganjurkan mestinya fasilitator kuasa dalam eksplorasi e-learning yang berpusat pada siswa menjadi media pembelajaran dan indera evaluasi yg efektif. Selain itu penelitian terdahulu terkait e-learning dilakukan oleh Ayu Yulita telah melewati tahapan validasi dengan persentase senilai $86,67 \%$ dari ahli materi, 92,39\% dari ahli media, dan 94,47\% dari ahli desain pembelajaran. Serta hasil uji praktikalitas perangkat e-learning menunjukkan adanya kepraktisan pada perangkat e-learning selaku media belajar yang mampu menyokong pemaparan materi dan tugas terstruktur peserta didik (Yulita, Ambarwulan dan Bakri, 2018). Penelitian terkini terkait fitur LMS Chamilo yang dilaksanakan oleh Izzah Tiari menggunakan model Alessi dan Trollip telah memperoleh hasil sebagai berikut: (1) fitur terkategori valid dengan persentase nilai oleh ahli media senilai $89,47 \%$, ahli materi senilai $84,62 \%$, dan ahli desain pembelajaran senilai $81,82 \%$; (2) e-learning terkategori praktis berdasarkan evaluasi oleh 3 peserta didik dengan variasi tingkat kognitif rendah, sedang, dan atas dengan rata-rata senilai $86,10 \%$; (3) e-learning terbukti sangat efektifi untuk membuat peningkatan hasil belajar peserta didik terlihat dari hasil $n$-gain senilai 0,70 masuk kategori tinggi (Tiari, dkk., 2020).

Dari penelitian terdahulu diatas didapatkan informasi bahwa LMS Chamilo mudah dalam pemasangannya, memiliki tampilan interface yang menarik, serta belum adanya pembelajaran fully online dari peneliti lain dan mereka masih melaksanakan pembelajaran didalam kelas. Peneliti telah melakukanpenelitian berdasarkan uraian diatas terkait efektivitas LMS Chamilo yang diajarkan secara fully online. Adapun penelitian ini dibatasi untuk materi gerak harmonik sederhana sukses menyokong pemaparan konten belajar dan tugas terpadu peserta didik. Perangkat pembelajaran yang dikembangkan terdiri atas: Silabus, Program Tahunan, Program Semester, Rencana Pelaksanaan Pembelajaran (RPP), Materi, dan Lembar Penilaian.

Permasalahan penelitian pada makalah ini yaitu bagaimana efektifitas LMS Chamilo materi gerak harmonik sederhana berdampak pada hasil belajar peserta didik. Adapun tujuan dari penelitian yaitu mengetahui efektifitas LMS Chamilo materi gerak harmonik sederhana terhadap hasil belajar peserta didik. Selanjutnya manfaat penelitian yakni: (1) Supaya peserta didik mendapat peningkatan hasil belajar mata pelajaran fisika; (2) bagi pendidik diharapkan perangkat e-learning menggunakan LMS Chamilo ini dijadikan wadah dan solusi mendidik pada pembelajaran jarak jauh; (3) bagi sekolah dibutuhkan akibat penelitian ini menjadi bahan evaluasi agar bisa menaikkan kualitas pembelajaran.

\section{METODE}

\section{Rancangan Penelitian}

Penelitian ini dikategorikan sebagai penelitian pre-eksperimen melalui One Group Pretest-Postest Design. Pada desain ini, pretes diberikan sebelumnya, kemudian setelah pretes kelompok diberi perlakuan berupa perangkat e-learning chamilo dan diakhir diberikan postes (Sugiyono, 2006). Peneliti menggunakan desain penelitian yang terpapar sebagai berikut.

$$
\begin{array}{lll}
\mathbf{O}_{1} \times \mathbf{O}_{2} & \text { Ket: } & \mathrm{O}_{1}=\text { Pretes } \\
& \mathrm{X}=\text { Perlakuan } \\
& \mathrm{O}_{2}=\text { Postes }
\end{array}
$$

\section{Subjek Penelitian}

Perangkat e-learning dimaksudkan sebagai subjek pengembangan produk dan pada tahap uji lapangan subjeknya ialah peserta didik kelas X SMA Aisyiyah 1 Palembang 
yang terlibat dalam pembelajaran mata pelajaran fisika. Keefektifan e-learning dilaksanakan oleh satu kelompok dengan jumlah 30 peserta didik.

\section{Tempat dan Waktu Penelitian}

Pelaksaanaan penelitian telah selesai di semester genap tahun ajaran 2019/2020 di kelas X SMA Aisyiyah 1 Palembang.

\section{Prosedur Penelitian}

Pengukuran hasil belajar peserta didik berdssarkan nilai pengetahuan dimaksudkan agar diketahui besarnya peningkatan hasil belajar yg terjadi pada siswa guna melihat keefektifan pembelajaran perangkatt e-learning menggunakan Chamilo dalam pembelajaran. pada termin ini hasil belajarr siswa berupaa pretest sebelum pembelajarann menggunakan Chamilo serta posttest selesainya pembelajaran memakai Chamilo. Data yang didapatkan dari pretest dan posttest dihitung dengan rumus berikut:

$$
\text { Nilai }=\frac{\text { Soal Benar }}{\text { Jumlah Soal }} \times 100
$$

Sesuai hasil hitung dari rumus diatas, maka penganalisisan dilakukan dengan berpacu pada gain dari normalisasi N-gain sang Hake (2002). Gain Hake yg dipaparkan Fadaei (2019)) dimaksudkan sebagai tolok ukur efektifitas terhadap bermacam teknik pedagogi buat pembelajaran tradisional maupunnembelajaran memakai media mirip e-learning. $\mathrm{N}$-gain dihitung menggunakan persamaan berikut:

$$
N_{\text {gain }}=\frac{\bar{x} \text { posttest }-\bar{x} \text { pretest }}{100-\bar{x} \text { pretest }}
$$

Keterangan

(Hake, 2002)

xpretest : rata-rata tes awal

xposttest : rata-rata tes akhir

Langkah-langkah analisis data hasil tes belajar terhadap perangkat e-learning menggunakan LMS Chamilo sebagai berikut:

1. memperoleh rata-rata nilai pretest dan posttest;

2. penghitungan gain dengan berpacu pada nilai pretest dan posttest; serta

3. melakukan pengelompokan kriteria tingkat hasil $\mathrm{N}$-gain sesuai Tabel 1 berikut.

Tabel 1. Kategori perolehan $N$-Gain Score

\begin{tabular}{cl}
\hline Kriteria Nilai $\boldsymbol{N}$-gain & Kategori \\
\hline Jika $N_{\text {gain }} \geq 0,7$ & Tinggi \\
\hline Jika $0,7>N_{\text {gain }} \geq 0,3$ & Sedang \\
\hline Jika $N_{\text {gain }}<0,3$ & Rendah \\
\hline (Fadaei, 2019) &
\end{tabular}

Kategori diatas untuk mengetahui tingkat keefektifitasan dari pengembangan perangkat e-learning. Jika hasil $\mathrm{N}$-gain mendapat kategori tinggi maka perangkat tersebut sangat efektif, jika sedang maka perangkat tersebut efektif dan jika rendah maka perangkat tersebut kurang/tidak efektif.

\section{HASIL DAN PEMBAHASAN}

Penelitian dilakukan secara daring dengan melibatkan 30 peserta didik kelas $X$ SMA Aisyiyah 1 Palembang. Hasil penelitian didapatkan dalam bentuk analisis nilai pretest dan posttest perangkat e-learning menggunakan LMS Chamilo.

\section{Analisis Hasil Pretest}

Pertemuan awal dimulai dengan pemberian soal sebanyak 20 soal berupa soal pilihan ganda, uraian, dan pilihan jawaban bebas. Setelah diberikan soal pretest peserta didik hasilnya tampak pada Tabel 2 yakni. 
Tabel 2. Rekapitulasi Hasil Pretest

\begin{tabular}{clcc}
\hline Nilai & Predikat & $\begin{array}{c}\text { Dengan } \\
\text { Huruf }\end{array}$ & $\begin{array}{c}\text { Jumlah } \\
\text { Peserta }\end{array}$ \\
\hline $90-100$ & Sangat Baiik & A & 0 \\
\hline $80 \quad 89$ & Baik & B & 0 \\
\hline $70-79$ & Cukup & C & 3 \\
\hline $60-69$ & Buruk & D & 9 \\
\hline $0 \quad 59$ & Sangat Buruk & E & 18 \\
\hline
\end{tabular}

Hasil pada data di atas menunjukkan terdapat banyak peserta didik belum mengetahui materi gerak harmonik sederhana maka butuh untuk diadakan pembelajaran dengan mengimplementasikan perangkat e-learning pada proses pembelajaran agar terjadi peningkatan pengetahuan yang akan memiliki dampak terhadap kenaikan kompetensi kognitif peserta didik terhadap materi gerak harmonik sederhana.

\section{Penggunaan E-learning}

Kegiatan pembelajaran dilalui peserta didik melalui pemanfaatan perangkat elearning ditampilkan pada dokumentasi berikut.

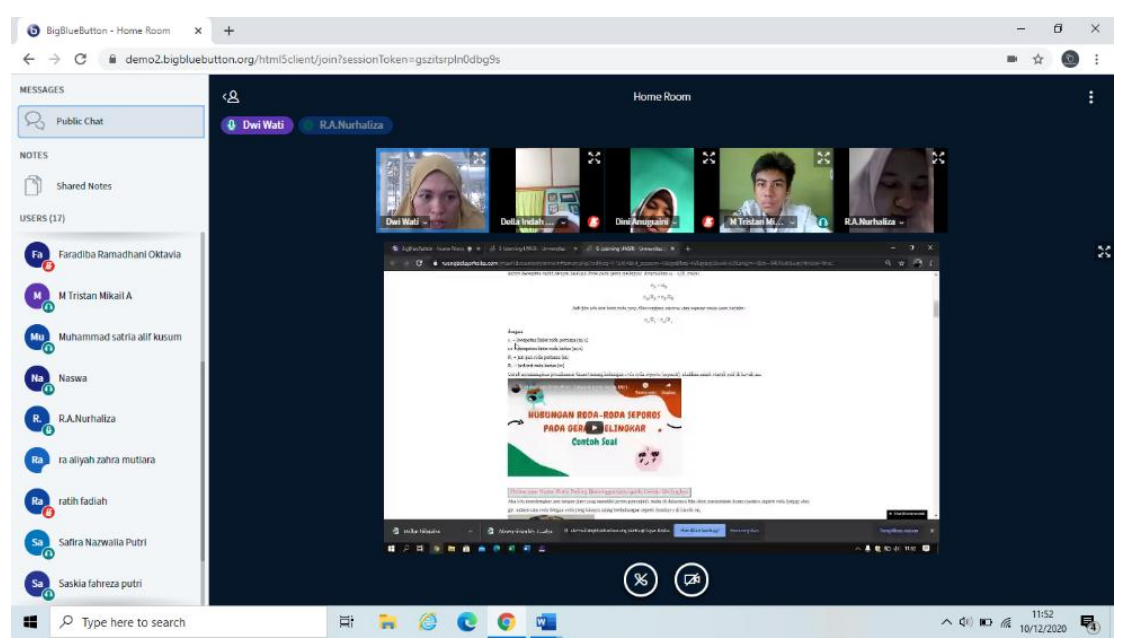

Gambar 1. Pemanfaatan E-Learning Pada Materi Gerak Harmonik Sederhana

\section{Analisis Hasil Posttest}

Pemberian soal Posttest dilaksanakan ketika peserta didik telah menyelesaikan kegiatan belajar menggunakan LMS Chamilo. Kegiatan posttest memasukkan 20 soal berupa soal pilihan ganda, uraian, dan pilihan jawaban bebas. Rekapitulasi hasil posttest terpaparkan pada tabel berikut:

Tabel 3. Rekapitulasi Hasil Posttest

\begin{tabular}{cccc}
\hline Nilai & Predikat & Dengan Huruf & $\begin{array}{c}\text { Jumlah } \\
\text { Peserta }\end{array}$ \\
\hline $90-100$ & Sangat Baiik & A & 5 \\
\hline $80-89$ & Baik & B & 14 \\
\hline $70-79$ & Cukup & C & 7 \\
\hline $60-69$ & Buruk & D & 3 \\
\hline $0-59$ & Sangat Buruk & E & 1 \\
\hline
\end{tabular}

Hasil paparan tabel diatas menunjukkan telah terdapat kenaikkan pada hasil belajar peserta didik pasca penggunaan e-learning menggunakan LMS Chamilo yang dapat digambarkan pada Gambar 4 sebagai berikut. 




Gambar 4. Perbandingan Rekapitulasi Nilai Pretest dan Nilai Posttest

Gambar diatas memperlihatkan selisih rekapitulasi pretest dan posttest yang menampilkan tersedianya peningkatan hasil belajar peserta didik pada kegiatan pretest sebelum penggunaan perangkat e-learning menggunakan LMS Chamilo dan posttest setelah penggunaan perangkat e-learning menggunakan LMS Chamilo.

\section{Analisis Keefektifan ( $N$-gain)}

Penilaian efektifitas dihitung melalui menganalisis nilai $\mathrm{N}$-gain disesuaikan dengan nilai rata-rata pretest dan posttest seperti tabel berikut.

Tabel 5. Rekapitulasi Rerata Pretest, Posttest, N-gain

\begin{tabular}{ccc}
\hline $\begin{array}{l}\text { Rerata } \\
\text { Pretest }\end{array}$ & Rerata Posttest & N-gain \\
\hline 51,00 & 79,00 & 0,582 \\
\hline Kategori & & Sedang \\
\hline
\end{tabular}

Uji lapangan/akibat belajar dilaksanakan dalam rangka menguji efektifitas dari perangkat e-learning menggunakan LMS Chamilo yg telah dikembangkan. akibat uji lapangan kepada 30 siswa kelas X SMA Aisyiyah 1 Palembang dilaksanakan melalui pretest dan posttest. Peningkatan akibat belajar terpaparkan pada rata-rata pretest peserta senilai 51,00 sebagai 79,00 pada yang akan terjadi posttest. Peningkatan tersebut mengungkapkan adanya peningkatannhasil belajar sebelum dannsesudah belajar menggunakan perangkat e-learning memakai LMS Chamilo. Peningkatan hasil belajar setelah memakai perangkat e-learning menggunakan LMS Chamilo terbukti efektif buat mempertinggi yang akan terjadi belajar siswa dengan nilai $\mathrm{N}$-Gain 0,582.

Akibat $\mathrm{N}$-gain selanjutnya dikategori sesuai Hake (2002) yaitu terdapat 3 kategori, Bila N-gain > 0,7 kategori tinggi; Bila 0,3 $\leq \mathrm{N}$-gain $\leq 0,7$ kategori sedang; Bila N-gain < 0,3 kategori rendah. Maka akibat $\mathrm{N}$-gain berada pada kategori sedang. hasil $\mathrm{N}$-gain senilai 0,582 tergolong kedalam kategori sedang mempresentasikan adanya penggunaan perangkat e-learning di pembelajaran motilitas harmonik sederhana secara daring memberikan dampak efektivitas yg baik terhadap hasil belajar siswa. Peningkatan hasil belajar dalam kategori sedang mendapat pengaruh dari pemanfaatan perangkat e-learning menggunakan LMS Chamilo pada kegiatan pembelajaran. Sesuai hasil angket respon peserta didik terhadap penggunaan perangkat e-learning menggunakan LMS Chamilo ditemukan masukan yang baik sebab bisa dikelola sesuai dengan keinginan peserta didik, konten pelajaran mudah dimengerti, serta terdapat video contoh soal yang tidak sulit untuk ditonton dan mendukung peningkatan pengetahuan peserta didik.

Perangkat e-learning sukses diteliti diatas, relevan dengan penelitian Pande dkk (2016) menyatakan fitur e-learning dalam pembelajaran sangat supell terhadap waktu serta kawasan. E-learning juga mampu membuahkan efesiensi pengetahuan 
meningkat dan berkualitas melalui mudahnya pengaksesan isu. Pande dkk (2016) jua memapaskan e-learning berpeluang pada menghubungkan antar siswa pada forum diskusi. Selain itu, e-learning memberikan kemudahan bagi siswa tahu konten pembelajaran sebab sudah terstruktur dalam satu sistem e-learning. Selanjutnya penelitian terbaru oleh Izzah Tiari (2020) pengembangan fitur e-learning berbasis Chamilo dikembangkan untuk SMK didapatkan bahwa fitur di LMS Chamilo menarik serta bisa menaikkan akibat belajar peserta didik.

\section{Kelebihan dan Kelemahan Penelitian}

Kelebihan dari penelitian pengembangan e-learning memakai LMS Chamilo diantaranya: 1) file flash mampu pribadi dimainkan dikomputer tanpa perlu diunduh terlebih dahulu; dua) Navigasi, bahasa dan desain tampilan praktis dipahami sebagai akibatnya mempermudah pengguna buat mengakses; tiga) ikon di E-learning menggunakan LMS Chamilo dapat diubah sesuai impian pendidik 4) pilihan template lebih variatif 5) dapat diakses menggunakan personal komputer juga smartphone; 6) Materi dapat diakses balik dimana saja serta kapan saja; dan 7) E-learning menggunakan LMS Chamilo terbukti dapat mempertinggi efektivitas dicermati berasal akibat belajar siswa dilihat pretest dan posttest yg diukur menggunakan $\mathrm{N}$-gain.

Penelitian pengembangan e-learning menggunakan LMS Chamilo terdapat kelemahan antara lain: 1) e-learning menggunakan LMS Chamilo cenderung tidak memuat aspek sosial pada pembelajaran; 2) fitur videoconference e-learning menggunakan LMS Chamilo tak bisa berfungsi dikarenakan spesifikasi yang rendah, sebagai akibatnya peneliti menautkan halaman asal big blue button supaya dapat melakukan tatap maya menggunakan siswa; tiga) file flash tidak bisa dimainkan dismartphone.

\section{KESIMPULAN}

Atas dasar hasil penelitian terkait Efektifitas Perangkat E-Learning menggunakan LMS Chamilo pada materi gerak harmonik sederhana untuk Sekolah Menengah Atas peneliti menyimpulkan bahwa perangkat e-learning menggunakan LMS Chamilo berefektivitas terkait peningkatan hasil belajar peserta didik yang pemaparannya pada kesenjangan evaluasi belajar antara nilai pretest dan posttest pada nilai $N g a i n$ yang masuk kategori sedang yaitu 0,582 .

\section{SARAN}

Berdasarkan hasil penelitian maka dapat disarankan beberapa hal berikut:

1. Perangkat e-learning menggunakan LMS Chamilo dapat dikembangkan terhadap mata pelajaran lain agar pemanfaatan dari LMS tersalurkan dalam menghadapi pembelajaran secara daring

2. Perangkat e-learning menggunakan LMS Chamilo dapat menjadi pedoman pengembangan e-learning lain serta mendapat penyempurnaan melalui domain berspesifikasi yang lebih tinggi.

3. Peneliti lain dapat mengembangkan LMS Chamilo dengan spesifikasi domain yang tinggi agar fitur videoconference dapat digunakan secara langsung tanpa penautan kelaman yang lain.

4. Peneliti lain dapat membuat file flash bisa dimainkan dismartphone bukan hanya dikomputer.

\section{DAFTAR PUSTAKA}

Ade, R. R., Markos, S. dan Ismet (2018) "Pengembangan Modul Elektronik Fisika Berbasis Multirepresentasi pada Materi Fluida Statis di Sekolah Menengah Atas," Jurnal Inovasi Pendidikan Ekonomi. doi: https://doi.org/10.36706/jip.v8i1.27.

Alam Fajar, N., Wati, P. dan Jaya, H. (2015) "Efektivitas Penggunaan Virtual Learning Terhadap Motivasi Dan Hasil Belajar Siswa Di Smk Negeri 2 Makassar," Jurnal PTK, 3((1)), hal. 1-14. 
Amelia, R. dan Gufron (2018) "E-learning design based on learning management system in web programming course," International Journal of Scientific and Technology Research, 7(9), hal. 106-109.

Bakri, F. dan Muliyati, D. (2017) "Pengembangan Perangkat E-Learning Untuk Matakuliah Fisika Dasar Ii Menggunakan Lms Chamilo," WaPFi (Wahana Pendidikan Fisika), 2(1). doi: 10.17509/wapfi.v2i1.4868.

Benevolo, C. dan Negri, S. (2007) "Evaluation of Content Management Systems (CMS): a Supply Analysis," on Information Technology Evaluation, 10(1), hal. 14.

Cahyati, F. D., Wibowo, A. M. dan Amelia, R. (2021) "Pengembangan Aplikasi Website Pokok Bahasan Ekosistem di Sekolah Dasar Brawijaya Smart School," Experiment: Journal of Science Education, 1(1), hal. 28-34. Tersedia pada: http://ejournal.uin-

malang.ac.id/index.php/experiment\%0Ahttp://creativecommons.org/licenses/by /4.0/\%0Ahttp://dx.doi.org/.

Chun-Hui, Wu., Chen, You-Shyang \& Chen, T. C. . (2017) "An Adaptive e-Learning System for Enhancing Learning Performance: Based on Dynamic Scaffolding Theory," Eurasia Journal of Mathematics, Science and Technology Education, (14. 10.12973/ejmste/81061.).

Elyas, A. H. (2018) "Penggunaan Model Pembelajaran E-Learning dalam Meningkatkan Kualitas Pembelajaran," Jurnal Warta, 56(04), hal. 1-11.

Ghoniemy, S., Fahmy, A. dan Aljahdali, S. (2010) "A Dedicated Web-Based Learning System," Journal of Computer Science and Engineering Technology, 1(2), hal. 84-92.

Hake, R. (2002) "Lessons from the physics education reform effort," Ecology and Society, 5(2). doi: 10.5751/es-00286-050228.

Hidayatulah, A., yushardi, Y. dan Wahyuni, S. (2015) "Pengembangan Bahan Ajar Berbasis Web Interaktif Dengan Aplikasi E-Learning Moodle Pada Pokok Bahasan Besaran Dan Satuan Di Sma," Jurnal Pembelajaran Fisika Universitas Jember, 4(2), hal. 139047.

Irawan, R. dan Surjono, H. D. (2018) "PENGEMBANGAN E-LEARNINGBERBASIS MOODLE DALAM PENINGKATKAN PEMAHAMAN LAGU PADA PEMBELAJARAN BAHASA INGGRIS," 5(1), hal. 1-11.

Istuningsih, W., Baedhowi dan Sangka, K. B. (2018) "The Use Of Electrinic Modules For Learning Effectiveness," Ijere, 03(03), hal. 75-85.

J.A. Hijar, M. et al. (2014) "Middleware to integrate heterogeneous Learning Management Systems and initial results," International Journal of Advanced Computer Science and Applications, 5(10), hal. 134-139. doi: 10.14569/ijacsa.2014.051019.

Jundu, R. et al. (2020) "Pengembangan Video Pembelajaran Ipa Berbasis Kontekstual Di Manggarai Untuk Belajar Siswa Pada Masa Pandemic Covid-19," LENSA (Lentera Sains): Jurnal Pendidikan IPA, 10(2), hal. 63-73. doi: 10.24929/lensa.v10i2.112.

Lin, M. H., Chen, H. C. dan Liu, K. S. (2017) "A study of the effects of digital learning 
on learning motivation and learning outcome," Eurasia Journal of Mathematics, Science and Technology Education, 13(7), hal. 3553-3564. doi: 10.12973/eurasia.2017.00744a.

Maes, J.-M. (2010) "Chamilo 2.0: A Second Generation Open Source E-learning and Collaboration Platform," International Journal of Advanced Corporate Learning (iJAC), 3(3), hal. 26-31. doi: 10.3991/ijac.v3i3.1364.

Mulqueeny, K. et al. (2015) "Incorporating effective e-learning principles to improve student engagement in middle-school mathematics," International Journal of STEM Education, 2(1), hal. 1-14 . doi: 10.1186/s40594-015-0028-6.

Pande, D., Wadhai, \& Thakare. (2016, February). E-Learning System and Higher Education. International Journal of Computer Science and Mobile Computing, 5(2), 274-280. Retrieved from www.ijcsmc.com

Pertiwi, F. T. dan Sumbawati, M. S. (2019) "Pengaruh Penggunaan Learning Management System Berbasis Chamilo dan Motivasi Terhadap Hasil Belajar Siswa SMK Kelas X Pada Mata Pelajaran Sistem Komputer," It-Edu, 3(02), hal. 88-97.

Puspita Sari, A. dan Setiawan, A. (2018) "The Development of Internet-Based Economic Learning Media using Moodle Approach," International Journal of Active Learning, 3(2), hal. 100-109. Tersedia pada: http://journal.unnes.ac.id/nju/index.php/ijal.

Putra, D. Y. S. dan Abidin, Z. (2020) "Pengembangan media website e-learning berbasis model responsive web design untuk siswa SMA," Agustus, 3(3), hal. 292-302. doi: 10.17977/um038v3i32020p292.

Rahmah, S. N., Saleh, M. dan Bharati, D. anggani L. (2020) "Edmodo and chamilo media in know-want-learned strategy to teach reading comprehension of recount texts to students with different reading habits," English Education Journal, 10(1), hal. 37-45. Tersedia pada: https://journal.unnes.ac.id/sju/index.php/eej/article/view/32814.

Sanova, A. (2018) "Learning Management System (LMS) Sebagai Aplikasi Pengembangan Materi Interaktif Pokok Bahasan Daur Biogeokimia Berbasis Computer Assisted Instruction.," Chempublish Journal, 3(1), hal. 21-31. doi: 10.22437/chp.v3i1.5078.

Sugiyono (2006) Metode Penelitian Pendidikan: Pendekatan Kuantitatif, Kualitatif, dan $R \& D$. Bandung: Alfabeta.

Sulisworo, D. et al. (2020) "A quick study on srl profiles of online learning participants during the anticipation of the spread of COVID-19," International Journal of Evaluation and Research in Education, 9(3), hal. 723-730. doi: 10.11591/ijere.v9i3.20642.

Surjono, H. D. (2013) Membangun Course E-Learning Berbasis Moodle. Yogyakarta: UNY Press.

Syah, R. H. (2020) "Dampak Covid-19 pada Pendidikan di Indonesia: Sekolah, Keterampilan, dan Proses Pembelajaran," SALAM: Jurnal Sosial dan Budaya Syar-i, 7(5). doi: 10.15408/sjsbs.v7i5.15314.

Syauqi, K., Munadi, S. dan Triyono, M. B. (2020) "Students' perceptions toward 
vocational education on online learning during the COVID-19 pandemic," International Journal of Evaluation and Research in Education, 9(4), hal. 881886. doi: 10.11591/ijere.v9i4.20766.

Tiari, I., Zulkardi, Z. dan Siahaan, S. M. (2020) "Pengembangan e-learning berbasis chamilo pada pembelajaran simulasi dan komunikasi digital," Jurnal Inovasi Teknologi Pendidikan, 7(1), hal. 1-11. doi: 10.21831/jitp.v6i2.28490.

Wu, C. H., Chen, Y. S. dan Chen, T. C. (2018) "An Adaptive e-learning system for enhancing learning performance: Based on dynamic scaffolding theory," Eurasia Journal of Mathematics, Science and Technology Education, 14(3), hal. 903913. doi: $10.12973 /$ ejmste/81061.

Yulita, A. R., Ambarwulan, D. dan Bakri, F. (2018) "Pengembangan E-Learning Menggunakan Chamilo Untuk Menyokong Proses Pembelajaran Fisika SMA Kelas X Semester II," Gravity : Jurnal IImiah Penelitian dan Pembelajaran Fisika, 4(2). doi: $10.30870 /$ gravity.v4i2.4029. 